\title{
A VARIABle SPEed PFC CONVERTER FOR BRUSHLESS SRM DRIVE
}

\author{
Mrs. M. Rama Subbamma ${ }^{1}$, Dr. V. Madhusudhan ${ }^{2}$, Dr. K. S. R. Anjaneyulu ${ }^{3}$ \\ and Dr. P. Sujatha ${ }^{4}$ \\ ${ }^{1}$ Professor, Department of E.E.E, G.C.E.T, Y.S.R Kadapa, A.P \\ ${ }^{2}$ Principal, K.O.R.M.C.E, Y.S.R Kadapa, A.P \\ ${ }^{3}$ Professor, Department of E.E.E, JNTUCE, Anantapur, A.P \\ ${ }^{4}$ Professor, Department of E.E.E, JNTUCE, Anantapur, A.P
}

\begin{abstract}
In many industrial applications Switched Reluctance Motor (SRM) is mainly used because of its high efficiency and low maintenance. Its mechanical structure is so simple to construct because it has salient poles, stator and rotor. Stator has concentrated winding and there is no winding on rotor. So therefore no need of commutator and brushes. The SRM drive has another advantage of fast dynamic response and fault tolerant capability. However since this drive requires DC excitation so we need to convert AC-DC, this AC$D C$ conversion imposes low power factor on grid side and this leads to high losses. Here we have consider air-compressor used for household applications. In this paper we are proposing PWM rectifier on AC side for Power factor correction the same rectifier is used for control of DC-link voltage. Also SRM motor is Driven by Asymmetrical converter, the speed of the Motor is changed by changing the DC-link voltage of Asymmetrical converter. A MATLAB/SIMULINK based model is developed for various loading conditions and simulation results are presented.
\end{abstract}

\section{KEYWORDS}

Switched Reluctance Motor (SRM), PWM (Pulse Width Modulation) Rectifier, Power Factor Correction

\section{INTRODUCTION}

In any machine torque can be produced by two ways, (i) Electromagnetic principle (ii) Reluctance principle. The example for the electromagnetic torque produced motor is Induction Motor. But it has disadvantage of low efficiency, high maintenance and no fault tolerant capability. These problems can addressed by using a Reluctance motor. In SRM we have only one winding placed on the stator, no winding on the rotor, so rotor can run at high speeds. But it has a disadvantage of low power factor when it is applied in air- conditioner applications[1]. This drawback is addressed in this paper. In previous literature Brushless DC motor(BLDC) is used in airconditioners, but it has disadvantage of high cost and lifetime of permanent magnets. In this research work we are proposing SRM in place of BLDC motor. Just like BLDC motor SRM requires converter for switching the phases. The input of the converter is DC supply, but in household applications the input is AC and we need to convert AC-DC[2-5]. One simple way to convert AC-DC is use of a Diode bridge rectifier but it has disadvantage of low power factor on AC side and pulsating DC on DC side. This problem is overcome by using many techniques in literature [7-10]. In this work we are proposing simplified PWM rectifier for power factor correction and DC voltage control. The proposed control strategy maintains almost unity power factor on AC side and constant DC on DC side. 


\section{OPERATION OF SRM}

The operation principle of the SRM is so simple; as current is flowing through one of the stator windings, the rotor pole try to align with the excited stator pole this will generates the torque. The direction of rotation is based on the order of the excited stator windings. Continuous torque can be obtained by synchronizing the each phase's excitation with rotor position. In order to get the reluctance torque the number of stator and rotor poles must be different. In this work we considered 6/4 pole SRM as shown in figure 1.

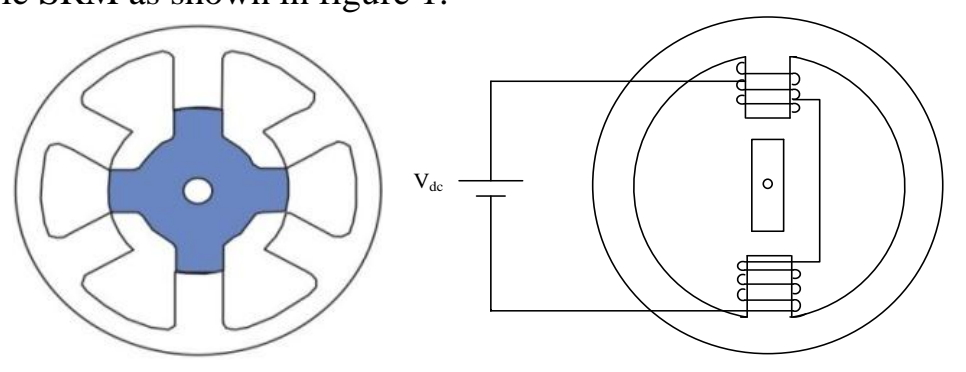

Fig.1. SRM with 6/4 pole. $\quad$ Fig.2. Aligned position

The SRM operation can be explained based on two positions (i)Aligned position (ii) unaligned position. Aligned position is position where the rotor pole is under the same axis of stator pole at this position flux is maximum and inductance is maximum as shown in figure 2.

Unaligned position is a position where rotor pole axis is in between stator pole axis as shown in figure 3. For motoring operation SRM phase winding is excited in unaligned position and deenergizes in aligned position.

\section{SRM CONVERTER}

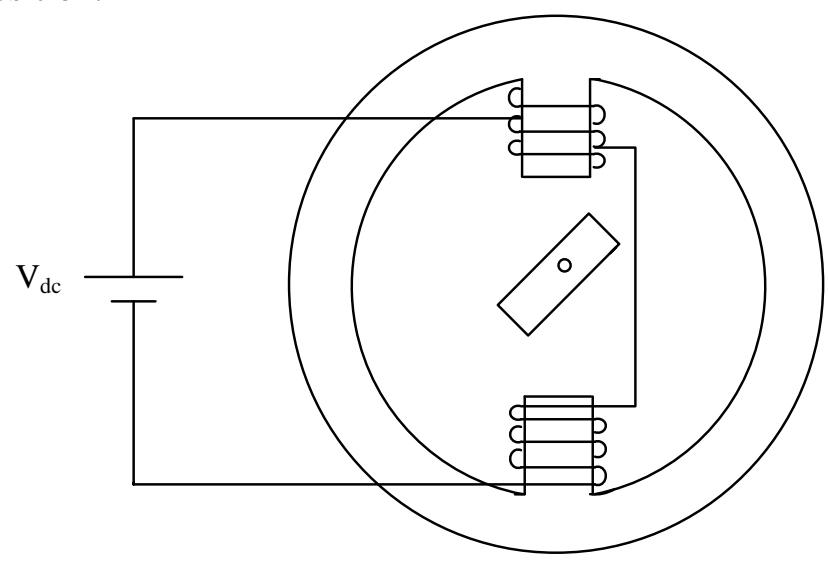

Fig.3. Unaligned position

For continuous rotation of rotor, we need to switch the phases based on rotor position for this we need a converter. There are various converters proposed in literature for simplicity we have considered asymmetrical converter as shown in figure 4. By turning on any two power switches in one winding circulates a current in that phase of SRM. Once the rotor reaches unaligned position the switches are turned off. In figure 4 by switching $S_{1} \& S_{2}$ we can excite phase A winding for current control we will turn $S_{2}$ continuously and switching the switch $S_{1}$. when the rotor reaches aligned position we will turnoff $S_{1} \& S_{2}$ then current is passing through $D_{1}$ and $D_{2}$ in the reverse direction to source. 


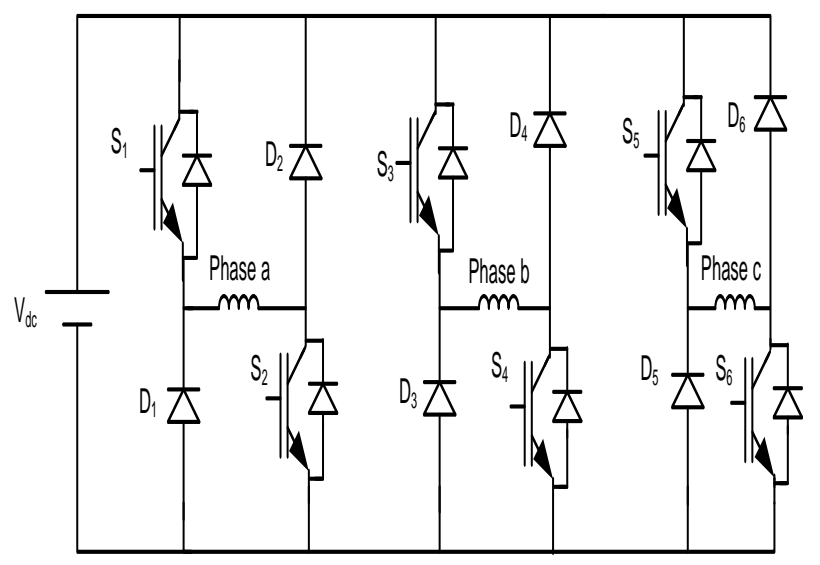

Fig.4. Asymmetrical converter for 6/4 SRM Drive

\section{RECTIFIER FED SRM DRIVE}

The conventional SRM fed with diode bridge rectifier shown in figure 5, on AC side it has diode bridge rectifier on motor side it has asymmetrical converter. This circuit has disadvantage of low power factor and low efficiency.

The proposed PWM rectifier fed SRM drive shown in figure 6. The frontend converter consist of four IGBT's controlled by power factor correction control strategy. The motor side asymmetrical converter is same as in figure 5. By varying the DC-Link voltage we are controlling the speed of the SRM.

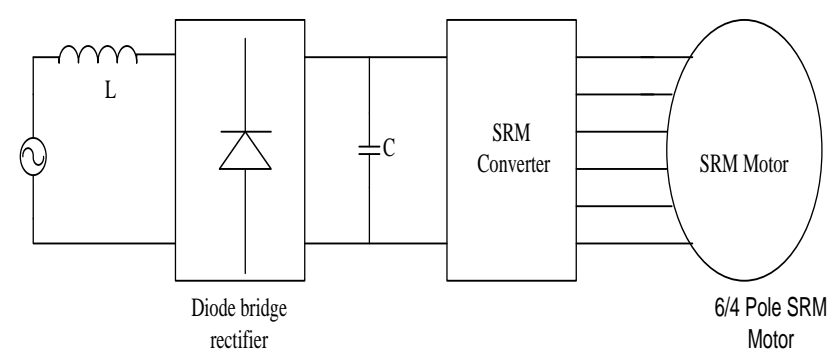

Fig.5. Conventional SRM drive

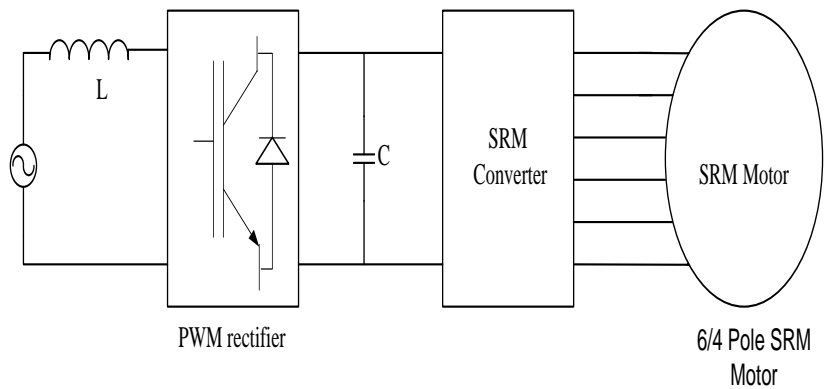

Fig.6. Proposed SRM drive

\section{DESIGN OF SRM DRIVE}

Here we consider 2KW SRM drive, the various components designed based on following equations 


\subsection{Selection of DC Link Voltage and Intermediate DC link Capacitor}

The VSC is supplied by a single-phase $220 \mathrm{~V}$ AC supply. The selection of minimum DC link voltage depends on amplitude of AC voltage and desired rated DC link voltage of a SRM Drive. $\mathrm{T}_{\mathrm{t}}$ must be greater than or equal to the peak value of supply voltage and equal to desired rated DC link voltage of the SRM Drive.

$$
V_{\text {de }} \geq V_{m}=V_{\text {rated }}
$$

Where $\mathrm{V}_{\mathrm{m}}$ is peak value of single-phase supply voltage and $\mathrm{V}_{\text {rated }}$ is desired rated DC link voltage of a power of the SRM Drive.

A 200V DC link is selected and for maintaining the constant DC link voltage, an intermediate DC link capacitor is used. The selection of a DC link capacitor is given as,

$$
C_{d e}=I_{d c} / 2 \omega V_{d e r i p p l e}
$$

where $I_{d c}$ is the DC link current which is obtained as,

$$
I_{d c}=\frac{P_{d c}}{V_{d c}}=10 \mathrm{~A}
$$

$\mathrm{w}$ is the angular frequency in rad/s and $\mathrm{V}_{\mathrm{dc}}$ ripple is the $\mathrm{I} \%$ of rated DC link voltage. The DC link capacitor is obtained as $1900 \mu \mathrm{F}$, using Eq. (2).

\subsection{Selection of Interface Inductor}

An interface inductor is used between AC supply and AC terminals of a single-phase VSC. The inductor is used to absorb PWM voltages. The fundamental rms voltage $\mathrm{V}_{\mathrm{c}}$ at VSC terminal is given as,

$$
V_{c}=\left(m V_{d c}\right) / \sqrt{2}
$$

Where $\mathrm{m}$ is modulation index, and it is considered $\mathrm{I}$. $\mathrm{V}_{\mathrm{dc}}$ is the reference DC link voltage (200V). The fundamental ms voltage at VSC terminals obtained as $282.88 \mathrm{~V}$ using Eq. (4). The relation between fundamental voltages at VSC terminals is given as, 


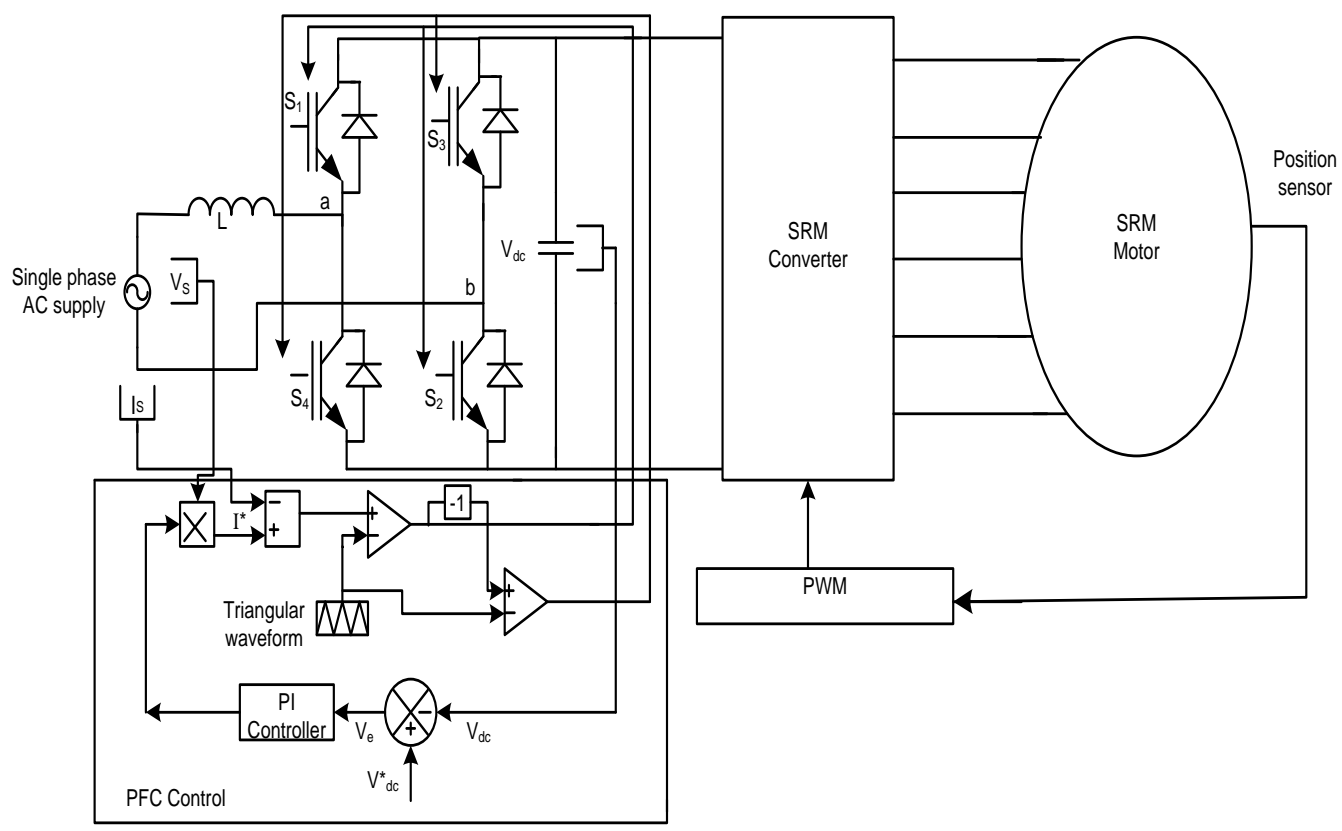

Fig.7.Control Scheme for PWM rectifier fed SRM Drive

$$
V_{c}=\sqrt{[} V_{s}^{2}+\left(I_{s}^{2} X_{1}^{2}\right)
$$

Where Vs is rms value of input supply voltage which is taken as $220 \mathrm{~V}$ and Is is rms value of supply current as,

$$
I_{s}=\frac{P_{\text {in }}}{V_{s}}=9.09 \mathrm{amp}
$$

Therefore, interface inductor is obtained using Eq. (5) is $17 \mathrm{mH}$.

\subsection{Design of Voltage Source converter (VSC)}

The voltage source converter (VSC) is designed on the basis of apparent power through the VSC. The rms current through each leg of VSC is obtained 9.09A using Eq. (6). Where $P_{\text {in }}$ the input power at VSC terminals. The maximum current through IGBTs is calculated as [18],

$$
I_{\max }=1.25\left\{I_{p-p}+\sqrt{2} I_{v s c}\right\}
$$

Considered $10 \%$ peak-peak ripple current, the maximum current through IGBT is obtained 17 Amp. Therefore 25A, 600V IGBT's are used for the VSC.

\subsection{Design of SRM converter}

The SRM converter consists of six IGBTs switches. The selection of IGBTs is based on rated current of a SRM. The stall current of SRM is $8.45 \mathrm{~A}$, as obtained from manufacturer data sheet and maximum current through IGBT in each phase is obtained as,

$$
I_{\max }=1.25\left\{I_{p p}+\sqrt{2} I_{v s i}\right\}
$$

Considered $10 \%$ peak-peak ripple in stall current, maximum current through IGBTs is obtained as 15A. Therefore 15A, 600V IGBT's are selected for a three-phase converter. 


\section{Mathematical Modelling OF SRM DRIVE}

The equivalent switched reluctance motor drive is shown in figure 8 . Here we have consider linear approximation it means we have neglected saturation effect. The induced emf across any phase is directly proportional to flux linked by the phase. The flux linked will depends on two parameters (i) rotor position and (ii)current.

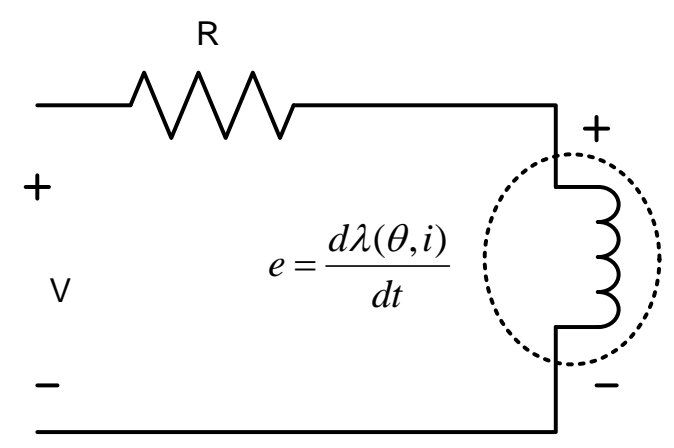

Fig.8. Equivalent circuit of switched reluctance motor

$$
V=R i+\frac{d \lambda\left(\theta_{,} i\right)}{d t}
$$

Where $\mathrm{V}$ is the applied phase voltage to phase, $\mathrm{R}$ is the phase resistance, and $e$ is back EMF. Ordinarily, $e$ is the function of phase current and rotor position, and flux $\lambda$ can be expressed as the product of inductance and winding current:

$$
\lambda(\theta, i)=i L(\theta, i)
$$

And from (8) the function can be rewritten as: $V=R i+\frac{d \lambda(\theta, i)}{d i} \frac{d i}{d t}+\frac{d \lambda\left(\theta_{i} i\right)}{d \theta} \frac{d \theta}{d t}$

The general torque expression is:

$$
\mathrm{T}(\theta, i)=\frac{\partial \int_{0}^{1} \lambda\left(\theta_{,} i\right)}{\partial \theta}
$$

In general, the dynamical model of a SRM is characterized by the rotor angular speed and angular position relationship:

$$
\begin{aligned}
& \omega=\frac{d \theta}{d t} \\
& \mathrm{~T}-T_{\text {load }}=J \frac{d \omega}{d t}+F \omega \\
& V=R i+L(\theta, i) \frac{d i}{d t}+i_{\omega} \frac{d L(\theta, i)}{d \theta}
\end{aligned}
$$

The average torque can be written depending on the number of phases of the SRM as:

$$
\mathrm{T}=\sum_{\text {phase }=1}^{n} T_{\text {phase }}
$$




\section{SimUlation ANALYSIS}

Case I: Diode Bridge based Switched Reluctance Motor.

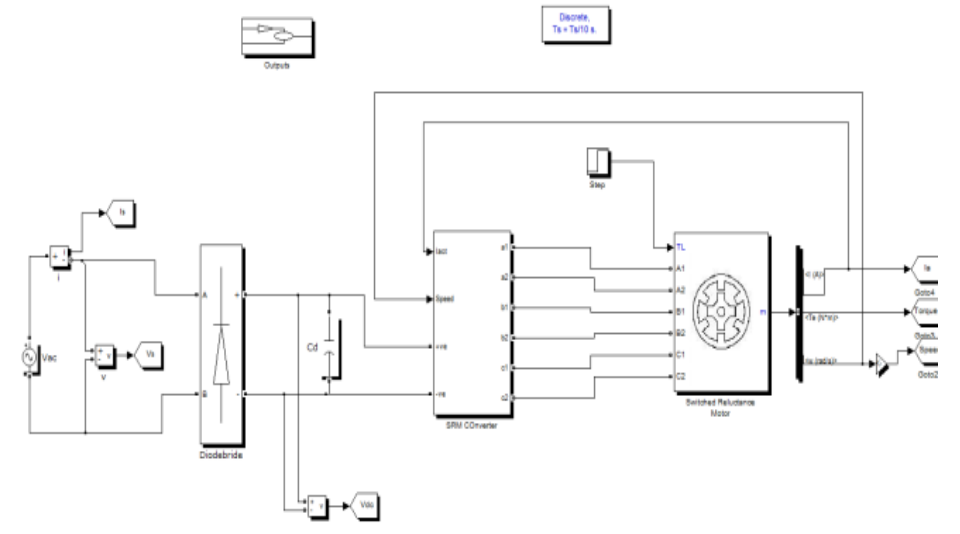

Fig.9. Simulation model of proposed SRM with Diode Bridge Rectifier

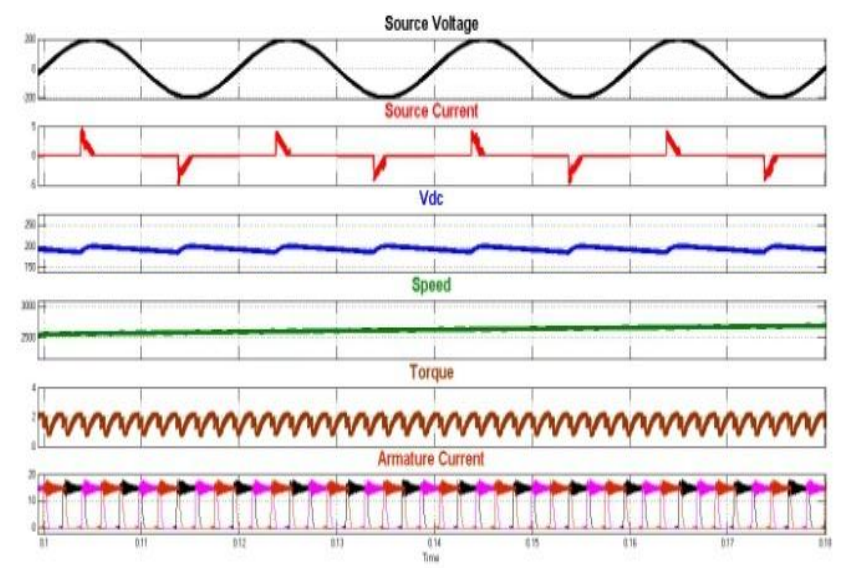

Fig.10. Simulation output waveforms of Source voltage, source current, rectifier output voltage, speed, torque and armature current of SRM

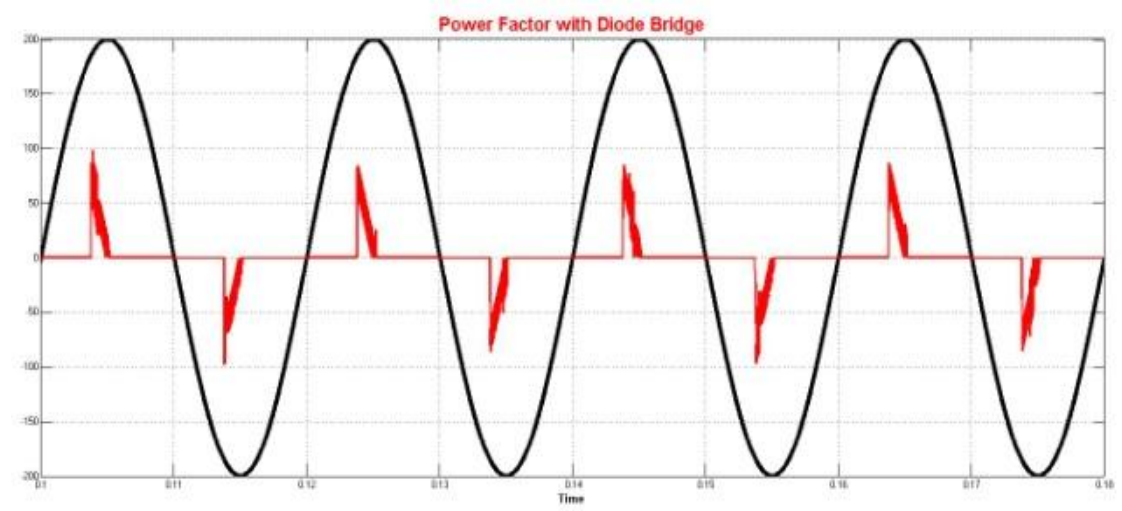

Fig.11. Simulation output wave form of Power factor with Diode Bridge Rectifier based SRM

Because of using Diode Bridge rectifier the load draws pulsating current from input side shown in fig.11, then voltage and current are not in a phase. So we achieve low power factor. 
International Journal on Cybernetics \& Informatics (IJCI) Vol. 5, No. 1, February 2016

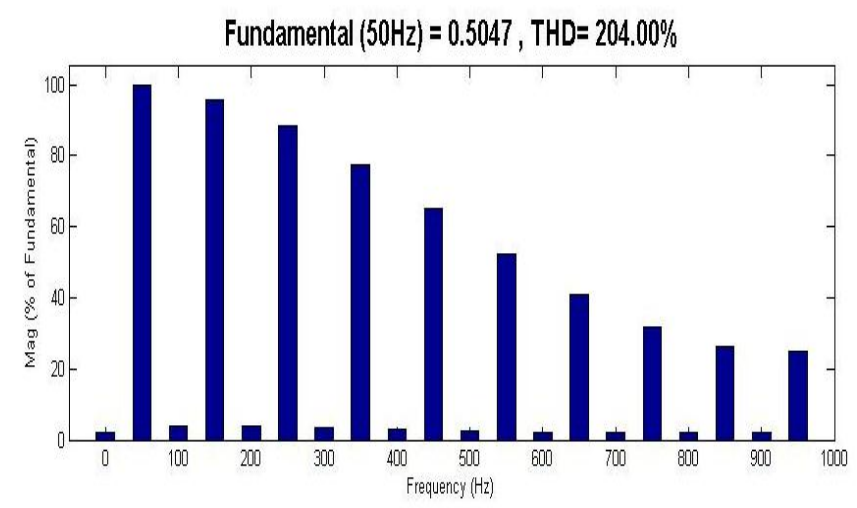

Fig.12. Total Harmonic Distortion of Source Current with Diode Bridge Rectifier based SRM Fig.12 shows the total harmonic distortion profile of input current, it is high because diode bridge rectifier is used at front end.

\section{Case II: PFC Rectifier based Switched Reluctance Motor at starting condition.}

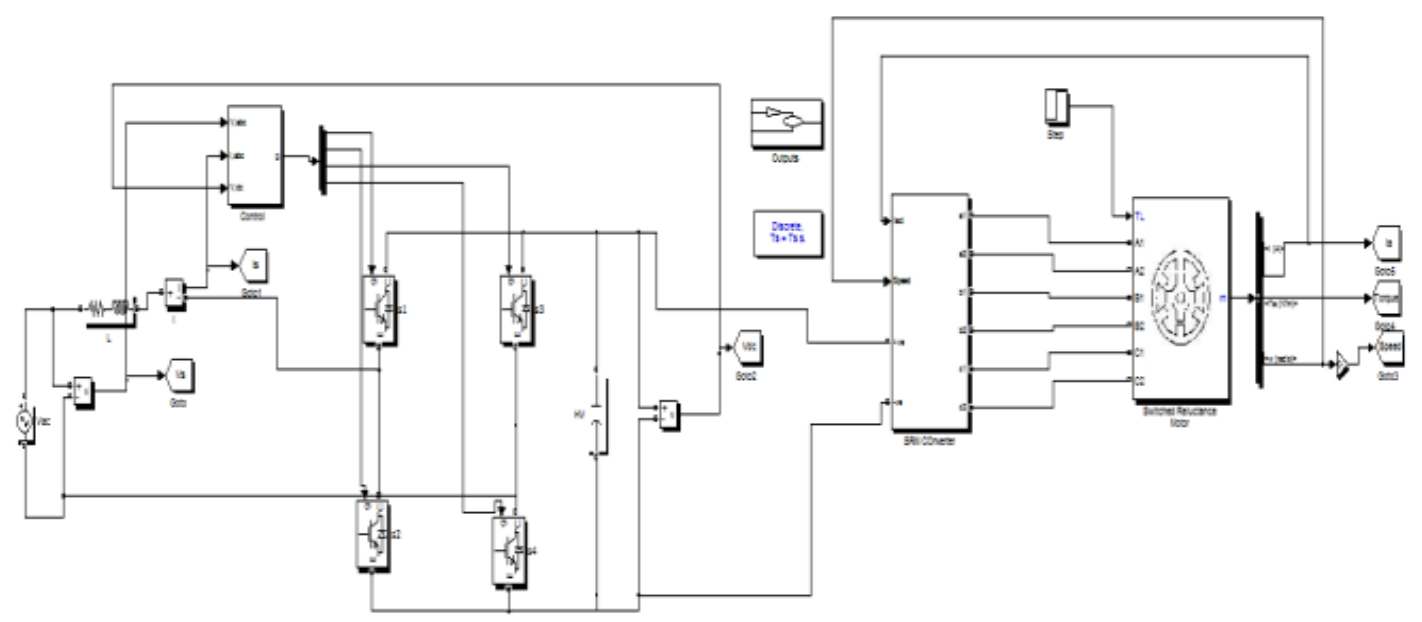

Fig.13. Simulation model of proposed SRM at starting condition with PFC Rectifier

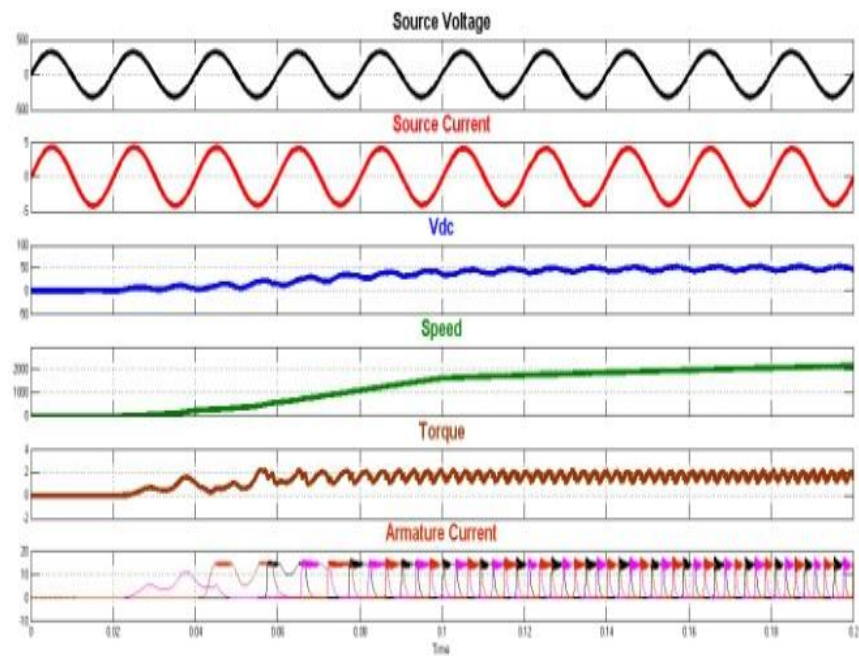

Fig.14. Simulation output waveforms of Source voltage, source current, rectifier output voltage, speed, torque and armature current of SRM 
International Journal on Cybernetics \& Informatics (IJCI) Vol. 5, No. 1, February 2016

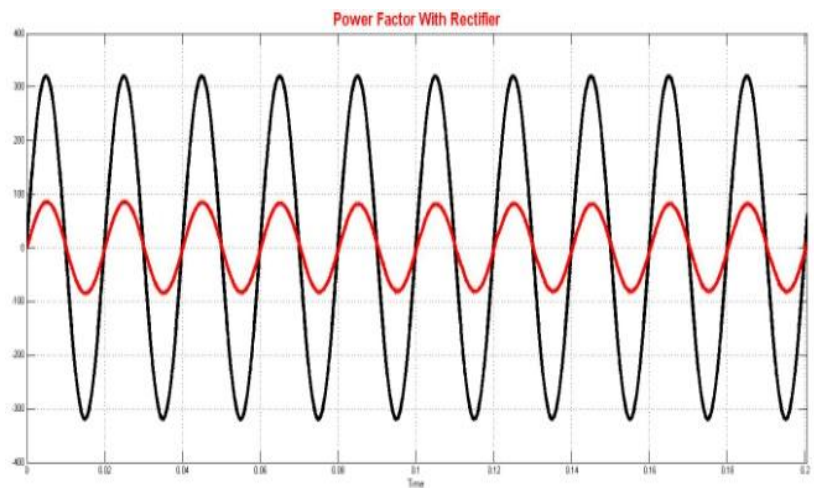

Fig.15. Simulation output wave form of Power factor with PFC Rectifier based SRM

Fig.15 shows the input voltage and current of PFC converter. These are in phase, then power factor is near to unity.

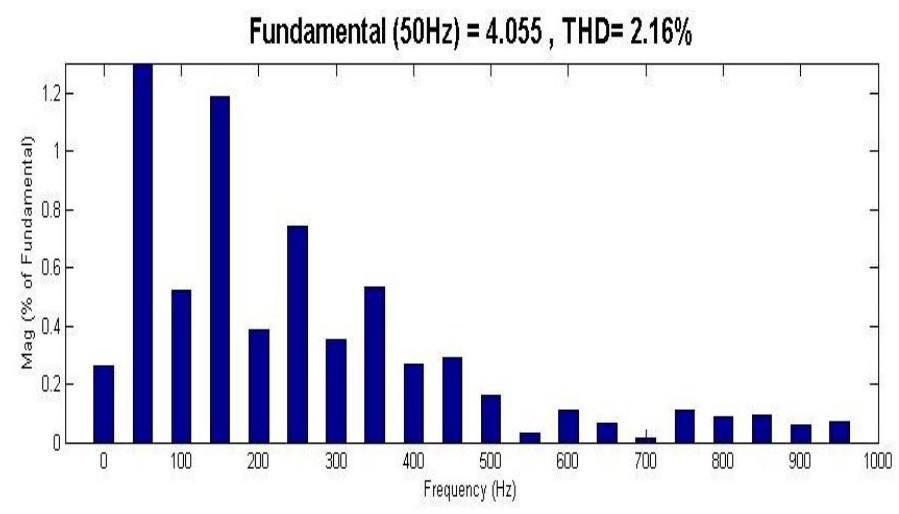

Fig.16. Total Harmonic Distortion of Source Current with PFC Rectifier based SRM

Fig.16 shows the total harmonic distortion profile for input current. It is lower value after using pfc converter at front end.

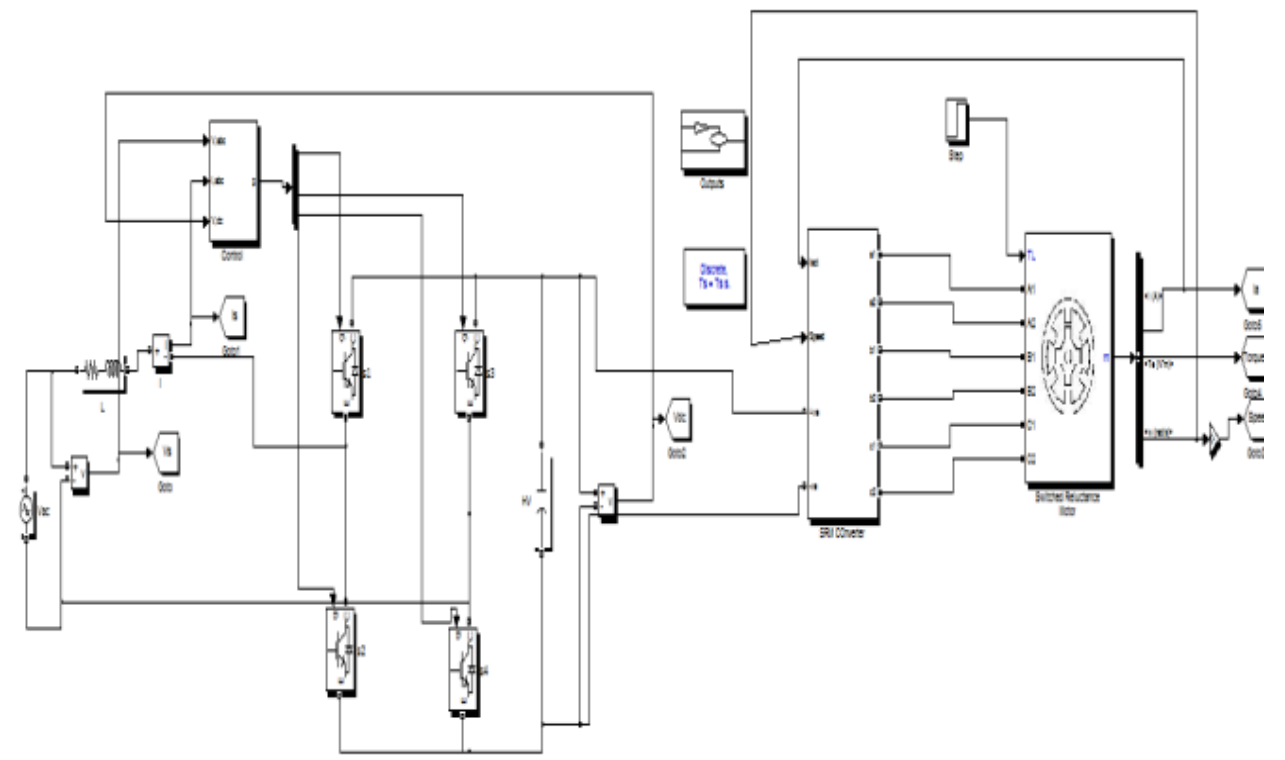

Fig.17. Simulation model of proposed SRM with PFC Rectifier at step variation of Voltage from 100V to $150 \mathrm{~V}$ 
International Journal on Cybernetics \& Informatics (IJCI) Vol. 5, No. 1, February 2016

Case III: PFC Rectifier based Switched Reluctance Motor with step variation of Voltage from $100 \mathrm{~V}$ to $150 \mathrm{~V}$.

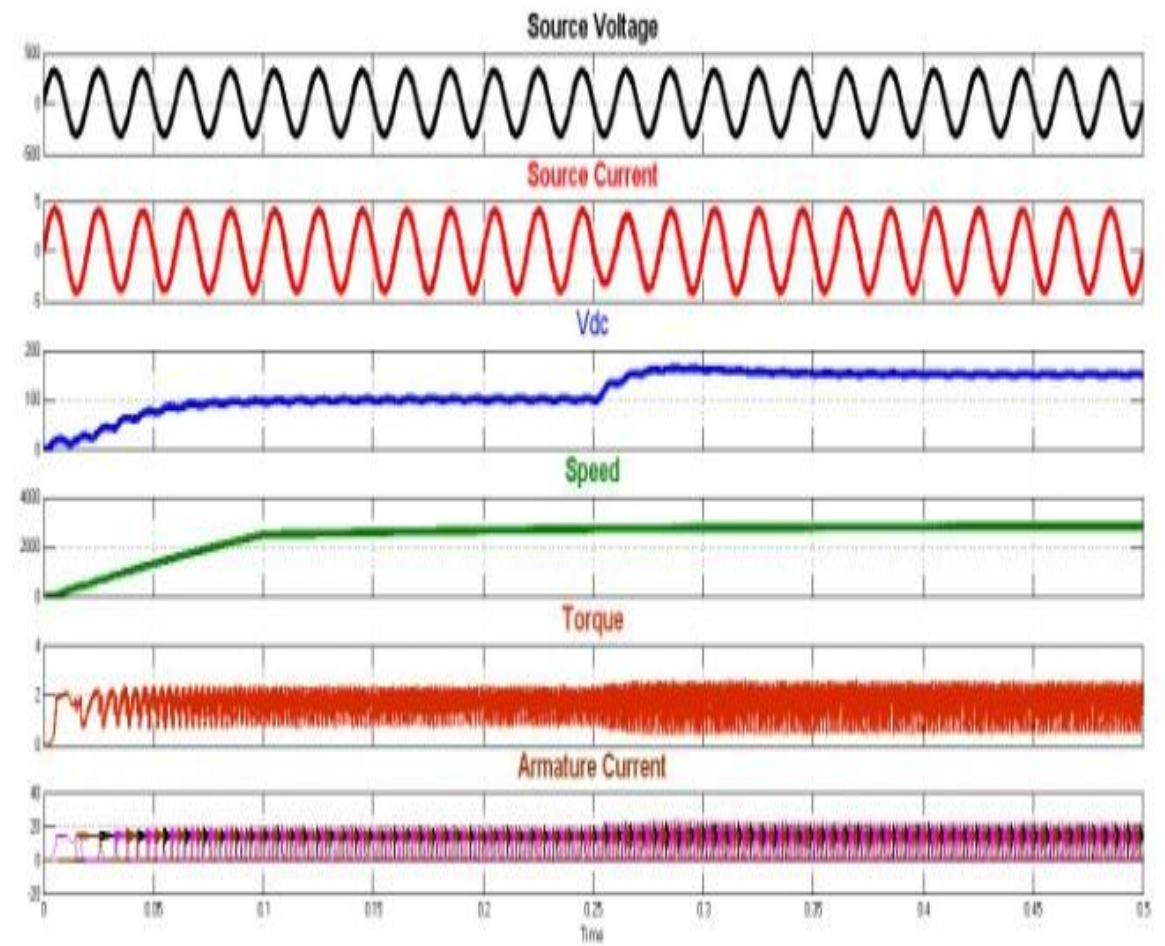

Fig .18. Simulation output waveforms of Source voltage, source current, rectifier output voltage, speed, torque and armature current of SRM at step variation of Voltage from $100 \mathrm{~V}$ to $150 \mathrm{~V}$

From fig. 18 we can show that if dc link voltage is varying from 100 to $150 \mathrm{~V}$, machine speed is does not change, speed is constant.

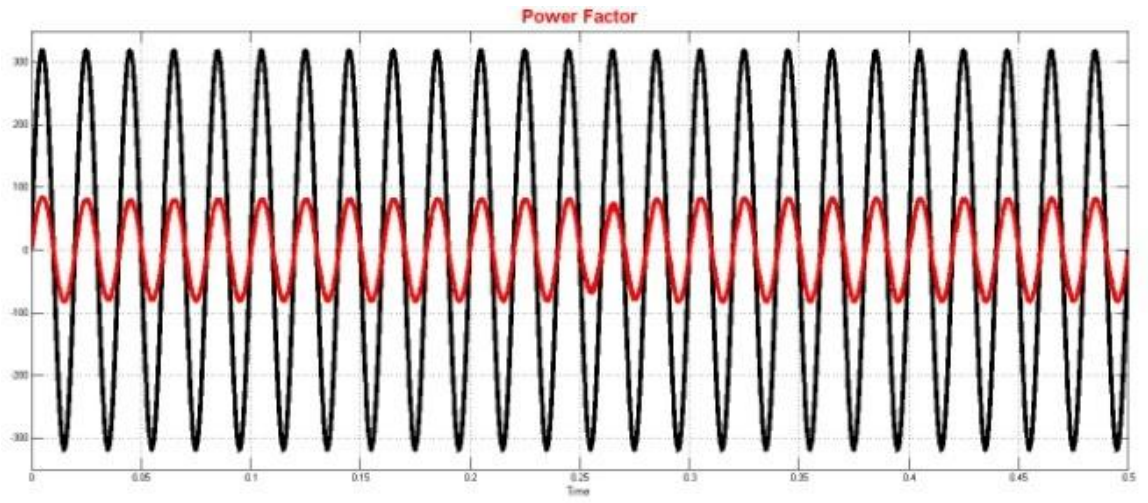

Fig.19. Simulation output wave form of Power factor with PFC Rectifier based SRM at step variation of Voltage from $100 \mathrm{~V}$ to $150 \mathrm{~V}$

From fig.19. We can show that if changing the dc link voltage, but power factor maintained constant, it is near unity. 
International Journal on Cybernetics \& Informatics (IJCI) Vol. 5, No. 1, February 2016

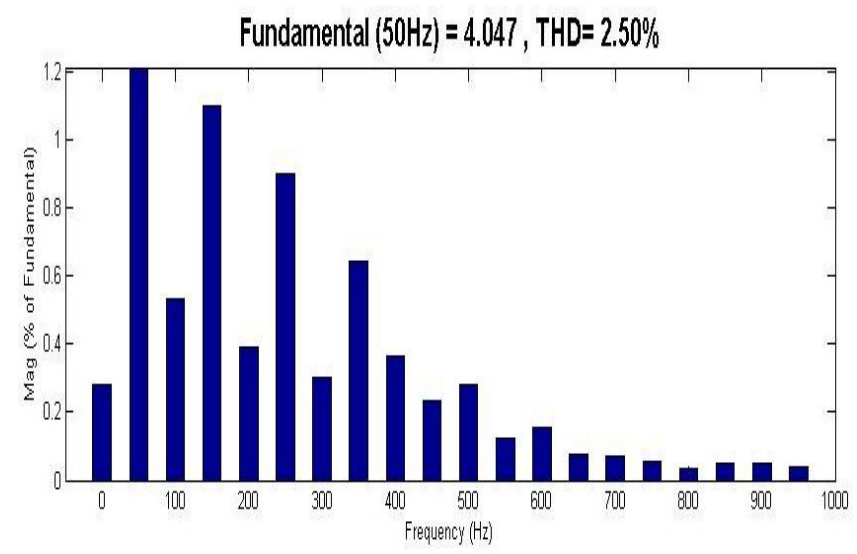

Fig.20.. Total Harmonic Distortion of Source Current with PFC Rectifier based SRM

Case IV: PFC Rectifier based Switched Reluctance Motor with 200 input Voltage.

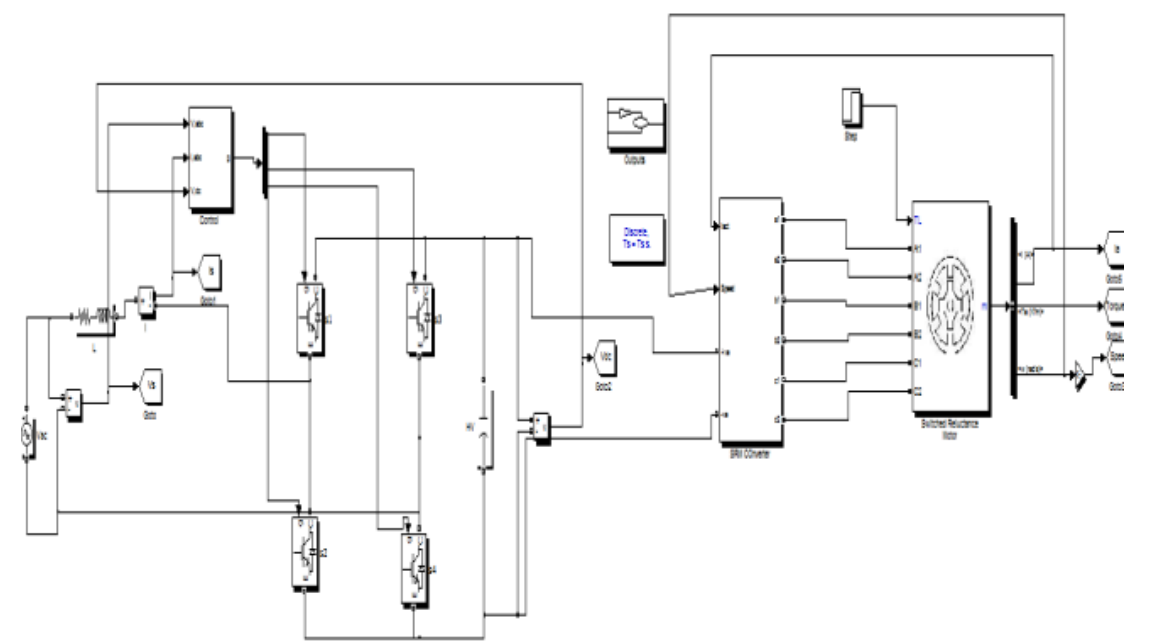

Fig.20. Simulation model of proposed SRM with PFC Rectifier with 200 input Voltage

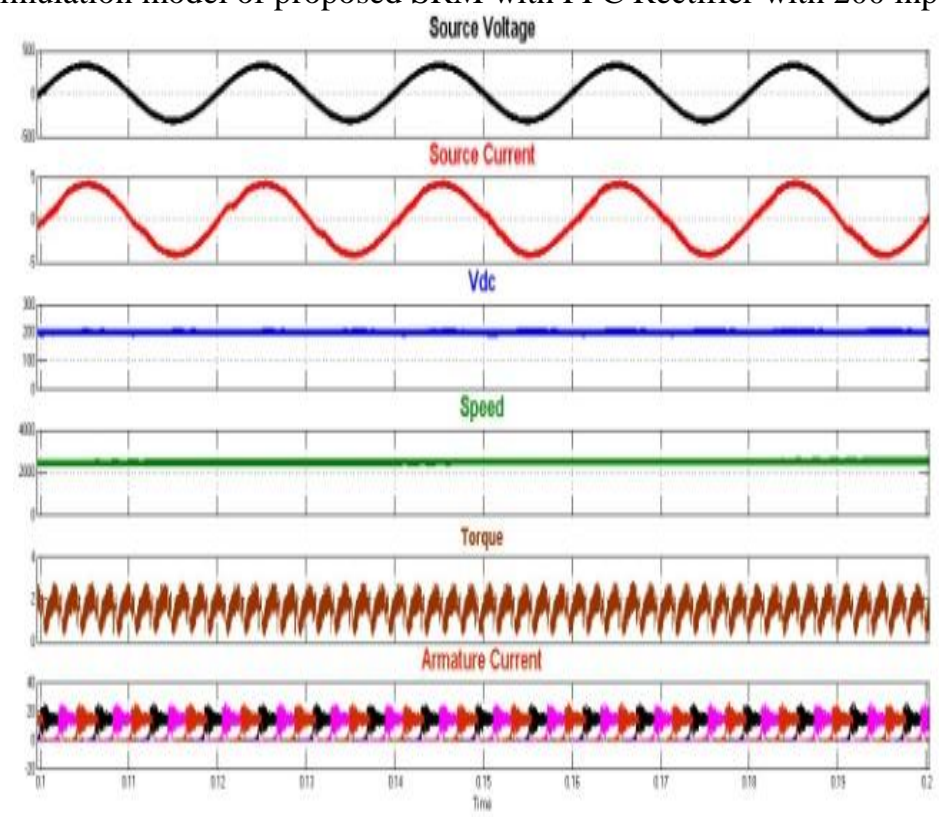

Fig.21. Simulation output waveforms of Source voltage, source current, rectifier output voltage, speed, torque and armature current of SRM with 200 input Voltage 
International Journal on Cybernetics \& Informatics (IJCI) Vol. 5, No. 1, February 2016

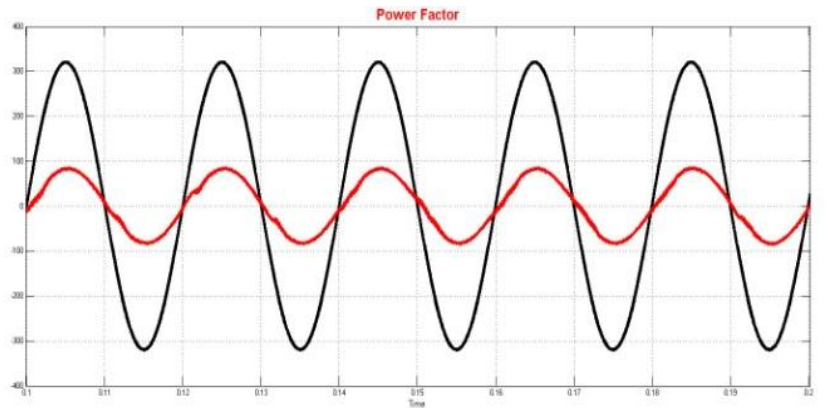

Fig.22. Simulation output wave form of Power factor with PFC Rectifier based SRM with 200 input Voltage

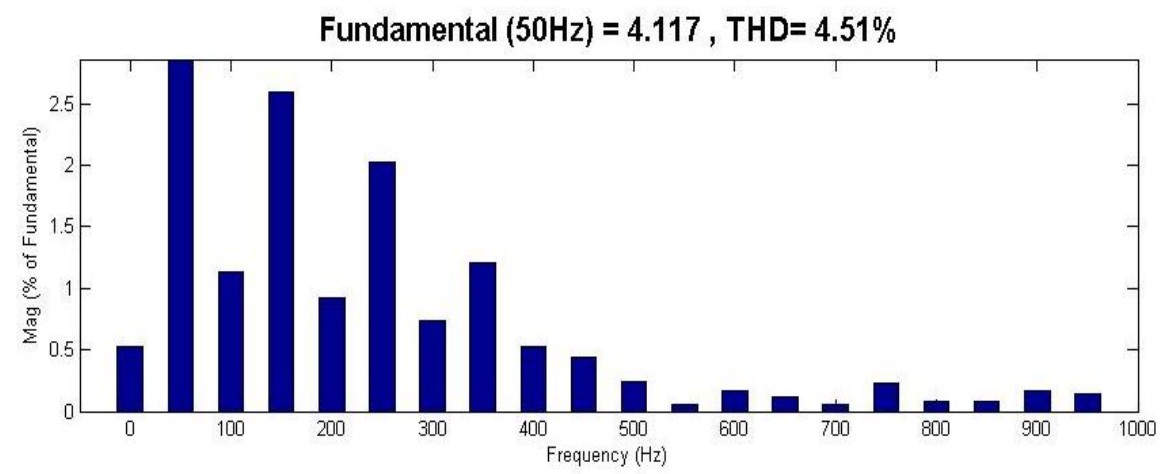

Fig.23. Total Harmonic Distortion of Source Current with PFC Rectifier based SRM

Fig.21 shows that switched reluctance motor characteristics like speed, torque and armature current in steady state. Fig. 22 shows that input power factor and fig. 23 shows THD profile.

Case V: PFC Rectifier based Switched Reluctance Motor with step variation of Voltage from $320 \mathrm{~V}$ to $220 \mathrm{~V}$.

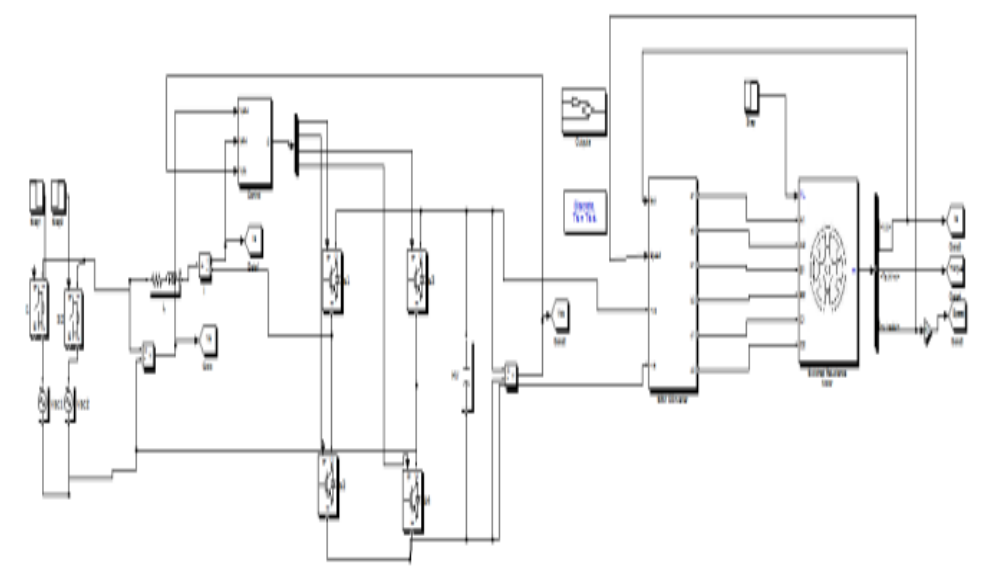

Fig.24. Simulation model of proposed SRM with PFC Rectifier at step variation of Voltage from 320V to $220 \mathrm{~V}$ 


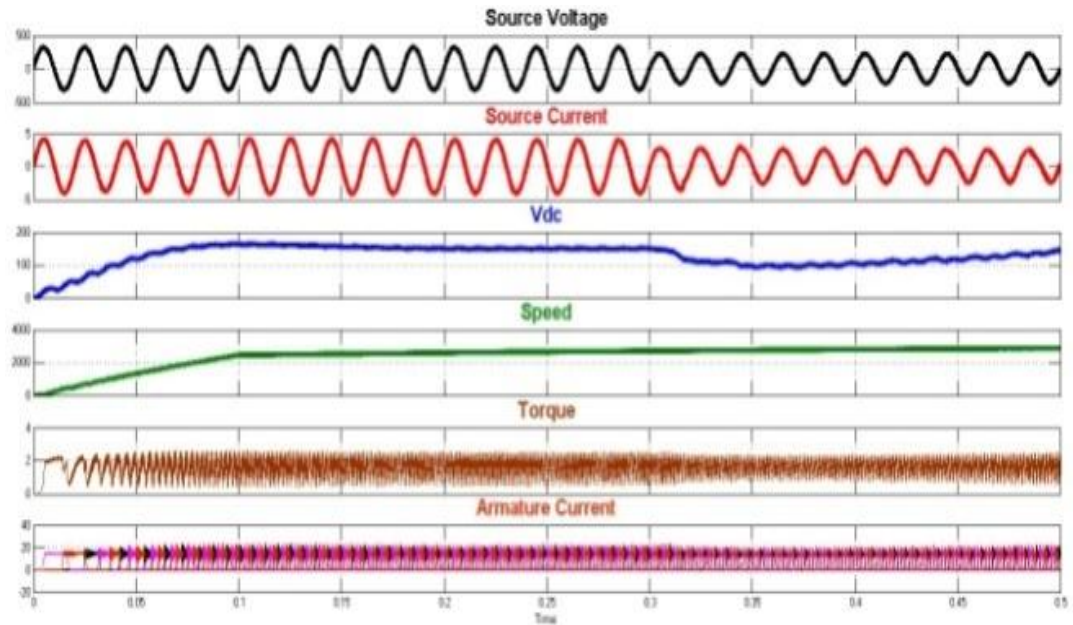

Fig.25. Simulation output waveforms of Source voltage, source current, rectifier output voltage, speed, torque and armature current of SRM at step variation of Voltage from $320 \mathrm{~V}$ to $220 \mathrm{~V}$

Fig.25 Shows that SRM characteristics, after changing the input voltage of PFC rectifier. If voltage is changed then speed does not change.

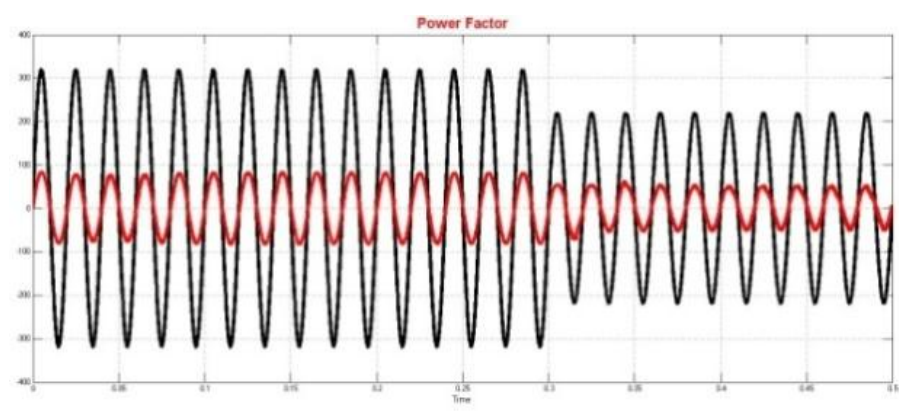

Fig.26. Simulation output wave form of Power factor with PFC Rectifier based SRM at step variation of Voltage from $320 \mathrm{~V}$ to $220 \mathrm{~V}$

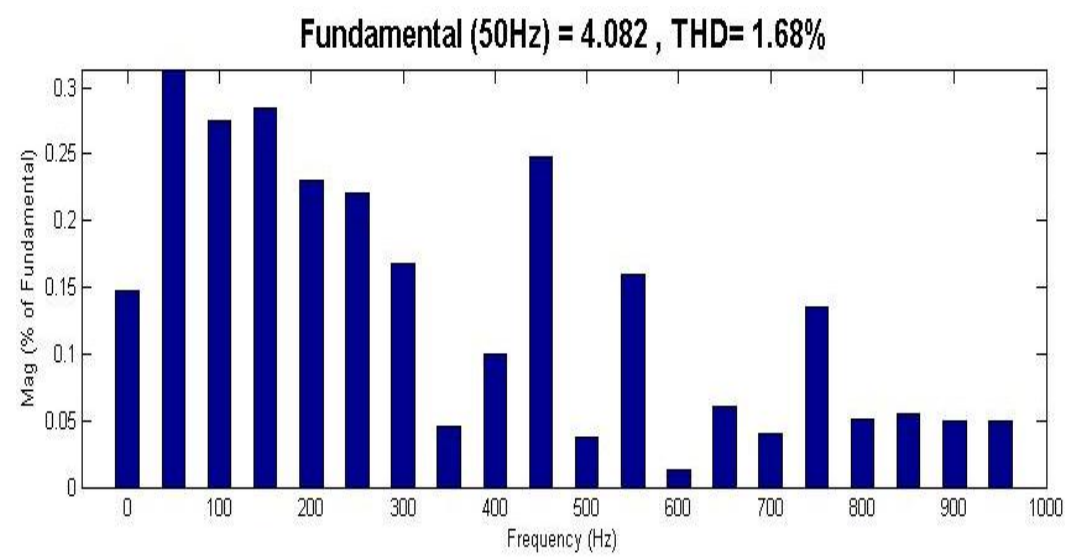

Fig.27. Total Harmonic Distortion of Source Current with PFC Rectifier based SRM.

Fig.26 shows that input power factor and fig.27 shows that THD profile of input current. 


\section{Conclusion}

Optimizing the switch angles in switched reluctance motor drives with PWM controller have been planned and successes with simulation implementation. The principle of operation, with parameters and PWM rectifier concerns and simulation results has been conferred. The switch on and switch off angles are used in PWM is optimized so as to get considered a high power factor SRM drives and to take care of the desired speed. To increase the ability issue of SRM drives is consummated by variable the switch on and turns off angles along with adjusting the typical voltage applied to the stator. The switch on and switch off angles is definitely enforced exploitation the PWM controller. The planned strategy is appropriate for both lower ratings and higher ratings of SRM drives. From the simulation analysis it's a good strategy to enhance the power factor for considered SRM drives.

\section{REFERENCES}

[1] Rashidi, M. M. Namazi, A. Bayat and S.M. Saghaiannejad "Power Factor Improvement Using Current Source Rectifier with Battery Charging Capability in Regenerative Mode of Switched Reluctance Motor Drives", in proc. 2013 IEEE conference.

[2] R. Krishnan, Switched Reluctance Motor Drives, Boca Raton, FL: CRC Press, 2001.

[3] M. Cacciato, A. Consoli, G. Scarcella and G. Scelba, "A switched reluctance motor drive for home appliances with high power factor capability," in Power Electronics Specialists Conference - PESC 2008, Jun 15-19, 2008, pp. $1235-1241$.

[4] W. K. Thong and C. Pollock, "Low-Cost Battery-Powered Switched Reluctance Drives with Integral Battery-Charging Capability," IEEE Trans. Industry Applications, Vol. 36, No. 6, pp 1676-1681, Nov./Dec. 2000.

[5] R. Krisinan, G. H. Rim, Modeling, "Simulation An Analysis Of Variable Speed Constant Frequency Power Conversion Scheme with A Permanent Magnet Brushless DC Generator," in Proc. 1988 IEEE Industrial Electronics Society Conf, IECON, pp. $332-337$.

[6] H.R. Karshenas, J. Mousavi, "A new direct sinusoidal input/output acac converter with unidirectional switches", in Proc. 2008 IEEE Electrical Machines and Systems Conf, pp. 1885-1890.

[7] Power Factor Improvement Using Current Source Rectifier with Battery Charging Capability in Regenerative Mode of Switched Reluctance Motor Drives.

[8] N. Mohan, M. Undeland, and W. P. Robbins, Power Electronics: Converters, Applications and Design. Hoboken, NJ: Wiley, 1995.

[9] J. Tseng and C. L. Chen, "A novel ZVT PWM Cuk power factor corrector," IEEE Trans. Ind. Electron., vol. 46, no. 4, pp. 780-787, Aug. 1999.

[10] Singh and G. D. Chaturvedi, "Analysis, design and development of single switch Cuk ac-de converter for low power battery charging application," in Proc. IEEE PEDES, 2006, pp. 16.

[11] L. Puttaswamy, B. Singh, and B. P. Singh, "Investigations on dynamic behavior of permanent magnet brushless de motor drive," Elect. Power Compon. Syst., vol. 23, no. 6, pp. 689-701, Nov. 1995. 